\title{
AEROSOL INVESTIGATION DURING THE ARCTIC HAZE SEASON OF 2018: OPTICAL AND MICROPHYSICAL PROPERTIES
}

\author{
Konstantina Nakoudi ${ }^{1,2^{*}}$, Christine Böckmann ${ }^{3}$, Christoph Ritter ${ }^{1}$, Vasileios Pefanis ${ }^{4,5}$, Marion \\ Maturilli $^{1}$, Astrid Bracher ${ }^{4,5}$, Roland Neuber ${ }^{1}$ \\ ${ }^{I}$ Alfred Wegener Institute, Helmholtz Center for Polar and Marine Research, Potsdam, Germany \\ ${ }^{2}$ Institute of Physics and Astronomy, University of Potsdam, Potsdam, Germany \\ ${ }^{3}$ Institute of Mathematics, University of Potsdam, Potsdam, Germany \\ ${ }^{4}$ Alfred Wegener Institute, Helmholtz Center for Polar and Marine Research, Bremerhaven, Germany \\ ${ }^{5}$ Institute for Environmental Physics, University of Bremen, Bremen, Germany \\ *konstantina.nakoudi@awi.de
}

\begin{abstract}
In this work, optical and microphysical properties of Arctic aerosol as well as their radiative impact are investigated. Air-borne Lidar observations along with ground-based measurements are evaluated for the Arctic Haze season of 2018. Aerosol abundance as inferred from particle backscatter was typical for this period of the year, with nearly spherical and large particles. The inversion of microphysical properties yielded high Refractive Index (RI) together with low SingleScattering Albedo (SSA), suggesting absorbing particles. A fitted lognormal volume distribution revealed a fine mode with effective radius $\left(r_{\text {eff }}\right)$ of $0.23 \mu \mathrm{m}$ and a coarse mode with $\mathrm{r}_{\text {eff }}=0.75 \mu \mathrm{m}$. The total radiative balance on ground was positive (12 $\mathrm{Wm}^{-2}$ ).
\end{abstract}

\section{INTRODUCTION}

Aerosol affect significantly the radiation budget, especially in the Arctic, where climate change is substantially accelerated as compared to lower latitudes, a phenomenon described as Arctic Amplification [1]. During Arctic springtime, aerosol concentration in the accumulation mode exhibits an annual maximum, forming the Arctic Haze [2]. The aim of this work is to investigate the optical and microphysical properties of Arctic aerosol and assess their radiative impact during spring.

\section{METHODOLOGY AND INSTRUMENTS}

\subsection{Lidar Systems}

The multi-wavelength system Koldewey Aerosol Raman Lidar (KARL) is installed in Ny-Ålesund, Svalbard Archipelago $\left(78.9^{\circ} \mathrm{N}, 11.9^{\circ} \mathrm{E}\right)$. KARL is a " $3 \beta+2 \alpha+2 \delta+2 w v$ " system equipped with a Nd:YAG laser emitting at 1064, 532 and $355 \mathrm{~nm}$ after frequency doubling and tripling, respectively [3]. The receiver consists of a $70 \mathrm{~cm}$-diameter telescope with a $1.75 \mathrm{mrad}$ field of view (FOV). Photomultiplier Tubes (PMTs) are used for the detection of backscattered photons in all channels, except for $1064 \mathrm{~nm}$, where Avalanche Photodiodes (APDs) are used. Signal acquisition is performed in both Photon Counting (PC) and Analog (A) mode, allowing for large dynamical detection range.
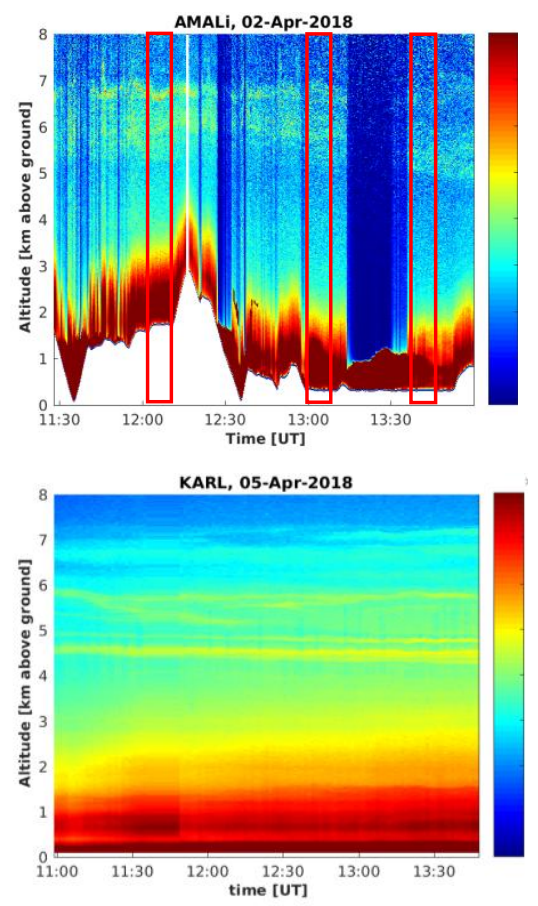

Figure 1: Lidar range-corrected signal (arbitrary units) at $532 \mathrm{~nm}$ over Fram Strait (top) and NyÅlesund (bottom). Rectangulars indicate temporal windows, for which optical properties were evaluated. 
The elastic system Air-borne Mobile Aerosol Lidar (AMALi) is installed on board of the research aircraft Polar 5, operated by the Alfred Wegener Institute (AWI) [4]. A Nd:YAG laser emits pulses at $15 \mathrm{~Hz}$ and a $10 \mathrm{~cm}$ off-axis telescope mirror with a $3.1 \mathrm{mrad}$ FOV collects backscattered light. PMTs are used for the detection of elastically backscattered photons at 532 and $355 \mathrm{~nm}$. Additionally, the crosspolarized component is recorded at $532 \mathrm{~nm}$. Licel Transient Recorders allow for high temporal resolution (1sec) in both PC and A mode. During Polar Air-borne Measurements and Arctic Regional Climate Model Simulation Project (PAMARCMiP) campaign in spring 2018 AMALi was in zenith measuring configuration.

Aerosol backscatter coefficient $(\beta)$ profiles were derived by the Klett method [5], while verticallyresolved retrievals of the aerosol extinction coefficient $(\alpha)$ were performed with the Raman technique [6]. KARL profiles were obtained with 2 min-7.5 $\mathrm{m}$ resolution. AMALi data were evaluated on a $5 \mathrm{~min}-7.5 \mathrm{~m}$ resolution, with restrictions regarding the flight altitude change. More specifically, after testing several combinations of vertical displacement and the corresponding vertical gradients, we concluded that a shift of $30 \mathrm{~m}$, has a negligible effect on the resulting profiles. Additionally, the profiles obtained by AMALi were vertically smoothed with a $37.5 \mathrm{~m}$ gliding average. In this study, we independently retrieved the aerosol optical properties from 3 AMALi profiles and, subsequently, estimated the average optical properties and their standard deviation within the altitude range of 5-6.9 km. Analogous approach was followed to retrieve the aerosol optical properties from KARL in altitudes of 4.4-6.9 km.

\subsection{Measurement Site}

Ny-Ålesund is the northernmost permanent research settlement, located on Spitsbergen Island, Svalbard Archipelago. Ny-Ålesund is affected by the warm West-Spitsbergen current, which is a sub-branch of the Gulf Stream, and thus experiences quite milder temperatures for the given latitude [7]. Furthermore, Ny-Ålesund is characterized by complex orography, since it is surrounded by Kongfjorden fjord in the North and mountain ranges (up to $1 \mathrm{~km}$ ) in the South, East and North direction. Strong topography is, hence, a challenge in closure of aerosol properties at the surface and in the atmospheric column [8].

\subsection{Microphysical Properties Inversion Scheme}

The model relating the optical parameters $\Gamma(\lambda)$ with the volume size distribution $\mathrm{v}(\mathrm{r})$ is described by a Fredholm integral operator of the first kind with a kernel function $\mathrm{K}(\mathrm{r}, \lambda, \mathrm{m})$ (Equation 1 ),

$$
\begin{aligned}
& \mathrm{K}(\mathrm{r}, \lambda, \mathrm{m})=\frac{3}{4 r} Q(r, \lambda, m) \\
& \Gamma(\lambda)=\int_{r_{\min }}^{r_{\text {max }}} K(\mathrm{r}, \lambda, \mathrm{m}) v(r) d r
\end{aligned}
$$

where $\lambda$ denotes the wavelength, $\mathrm{r}$ the particle radius, $\quad \Gamma(\lambda)$ stands for either the aerosol extinction or backscatter coefficient, while $Q(r, \lambda, m)$ stands for either the extinction or backscatter Mie efficiency (dimensionless). The input for microphysical properties retrieval was obtained by KARL system. More specifically, 5 discrete values were provided i.e. aerosol $\beta$ at 3 wavelengths $\left(\beta_{355}, \beta_{532}\right.$ and $\left.\beta_{1064}\right)$ and aerosol $\alpha$ at 2 wavelengths $\left(\alpha_{355}, \alpha_{532}\right)$. Identifying $\Gamma(\lambda)$ as our measurement data and $\mathrm{v}(\mathrm{r})$ as the unknown volume distribution, the problem reduces to the inversion of Eq. (1). Knowing the volume distribution, we can then extract the following microphysical parameters

Total surface-area concentration $\left(\mu \mathrm{m}^{2} \mathrm{~cm}^{-3}\right)$

$$
s_{t}=3 \int \frac{v(r)}{r} d r
$$

Total volume concentration

$$
v_{t}=\int v(r) d r
$$

$\left(\mu \mathrm{m}^{3} \mathrm{~cm}^{-3}\right)$

Total number concentration $\left(\mathrm{cm}^{-3}\right)$

$$
n_{t}=\frac{3}{4 \pi} \int \frac{v(r)}{r^{3}} d r
$$

Effective radius $(\mu \mathrm{m})$

$$
r_{e f f}=3 \frac{v_{t}}{s_{t}}
$$


Additionally, the complex RI and $\mathrm{SSA}_{355,532}$ can be retrieved. More details about the Lidar inversion code can be found in [9], [10] and [11].

\subsection{Radiation Measurements}

A BSRN (Baseline Surface Radiation Network) station is in operation since 1992 in Ny-Ålesund [12]. A CMP22 Pyranometer is measuring broadband $(0.2-3.6 \mu \mathrm{m})$ diffuse, global and reflected radiation. A CHP1 Pyrheliometer is used for monitoring broadband $(0.2-4 \mu \mathrm{m})$ direct fluxes, while a Pyrgeometer is measuring downward and upward fluxes $(3.5-50 \mu \mathrm{m})$.

\section{RESULTS}

\subsection{Aerosol Optical Properties}

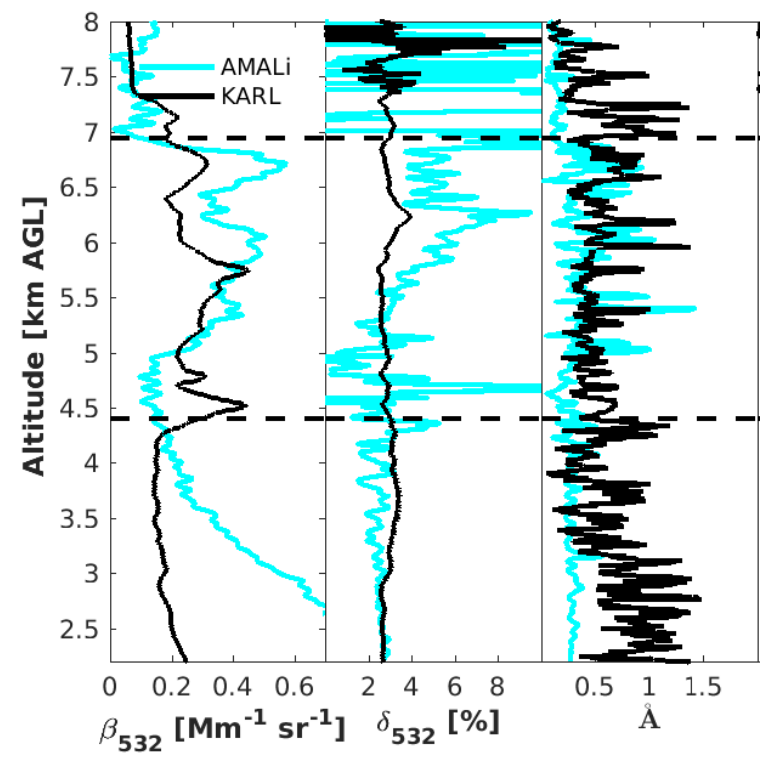

Figure 2: Vertically resolved optical properties as inverted from AMALi and KARL.

The investigated layers were observed over Fram Strait (2 April) and Ny-Ålesund (5 April) at approximately $4.5-7 \mathrm{~km}$ (Fig. 1). The inversion of aerosol optical properties (Fig. 2) yielded a bit higher $\beta$ coefficient over Fram Strait $\left(\beta_{532}^{A M A L i}=\right.$ $\left.0.39 \pm 0.17 \mathrm{Mm}^{-1} \mathrm{sr}^{-1}\right)$ compared to $\mathrm{Ny}$-Ålesund $\left(\beta_{532}^{K A R L}=0.28 \pm 0.09 \mathrm{Mm}^{-1} \mathrm{sr}^{-1}\right)$. Regarding backscattering at $355 \mathrm{~nm}$ (not shown here), this also exhibited higher values over Fram Strait $\left(\beta_{355}^{A M A L i}=1.25 \pm 0.4 \quad \mathrm{Mm}^{-1} \mathrm{sr}^{-1} ; \quad \beta_{355}^{K A R L}=\right.$ $\left.0.62 \pm 0.24 \mathrm{Mm}^{-1} \mathrm{sr}^{-1}\right)$. Nearly spherical particles were indicated by the linear depolarization ratio, with average values $( \pm 1 \sigma) \delta_{532}^{A M A L i}=4.5( \pm 2.6)$ $\%$ and $\beta_{532}^{K A R L}=2.8( \pm 0.6) \%$ over Fram Strait and Ny-Ålesund, respectively. Ångstrom ( $\AA$ ) exponent $\left(\beta_{355} / \beta_{532}\right)$ indicated aerosol with a size parameter close to unity. These particles are expected to exhibit low spectral dependency in their interaction with light. The average Lidar ratio (LR) at $355 \mathrm{~nm}$ was $42 \mathrm{sr}$, with polluted continental aerosol expected to have similar optical impact [13].

\subsection{Aerosol Microphysical Properties}

The retrieved RI (Tab. 1) was quite higher compared to other transport events into the Arctic, indicating higher absorption [14]. Besides, SSA was somewhat lower in comparison to typical Haze periods, suggesting more absorbing aerosol [15]. The fine aerosol mode was characterized by high surface-area and volume concentration and, consequently, exhibited higher number concentration compared to the coarse mode (Fig. 3). However, coarse particles have high potential of dominating the total scattering efficiency of the layer. In validating the latter hypothesis, Mie code calculations are necessary.

Table 1: Aerosol preliminary microphysical properties for the fine and coarse aerosol mode.

\begin{tabular}{|c|c|c|}
\hline $\begin{array}{c}\text { Microphysical } \\
\text { Properties } 355 \mathrm{~nm}\end{array}$ & \multicolumn{2}{|c|}{$\operatorname{Mean}( \pm 1 \sigma)$} \\
\hline RI & \multicolumn{2}{|c|}{$\begin{array}{c}1.63+\mathrm{i} \cdot 0.03 \\
( \pm 0.01+\mathrm{i} \cdot 0.002)\end{array}$} \\
\hline \multirow[t]{2}{*}{ SSA } & \multicolumn{2}{|c|}{$\begin{array}{l}0.83( \pm 0.0003), 355 \mathrm{~nm} \\
0.87( \pm 0.0002), 532 \mathrm{~nm}\end{array}$} \\
\hline & fine & coarse \\
\hline$r_{\text {eff }}(\mu \mathrm{m})$ & 0.23 & 0.75 \\
\hline $\mathrm{n}_{\mathrm{t}}\left(\mathrm{cm}^{-3}\right)$ & 50.3 & 0.04 \\
\hline $\mathrm{s}_{\mathrm{t}}\left(\mu \mathrm{m}^{2} \cdot \mathrm{cm}^{-3}\right)$ & 23.7 & 0.24 \\
\hline
\end{tabular}



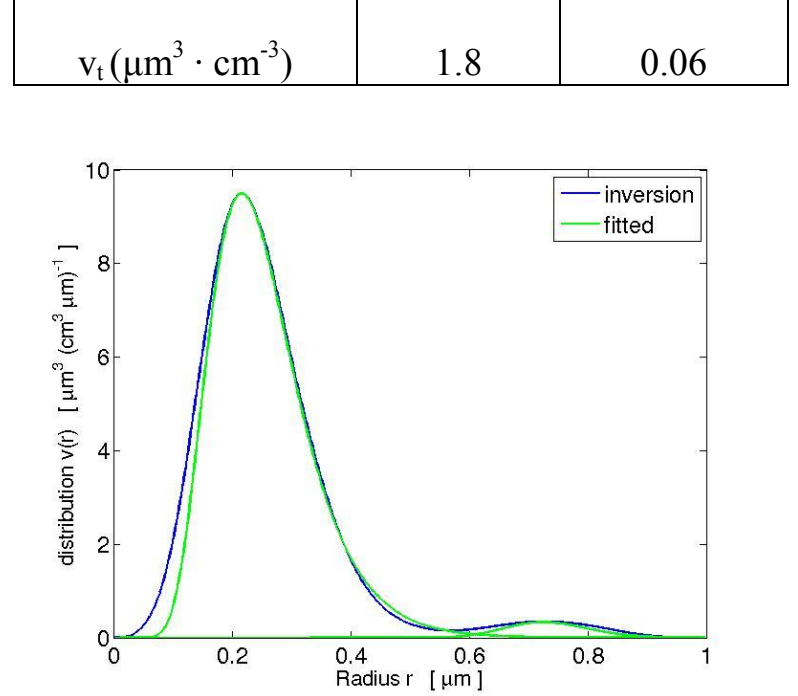

Fig 3: Retrieved volume distribution and lognormal fits for the fine and coarse aerosol mode.

\subsection{Radiative Overview}

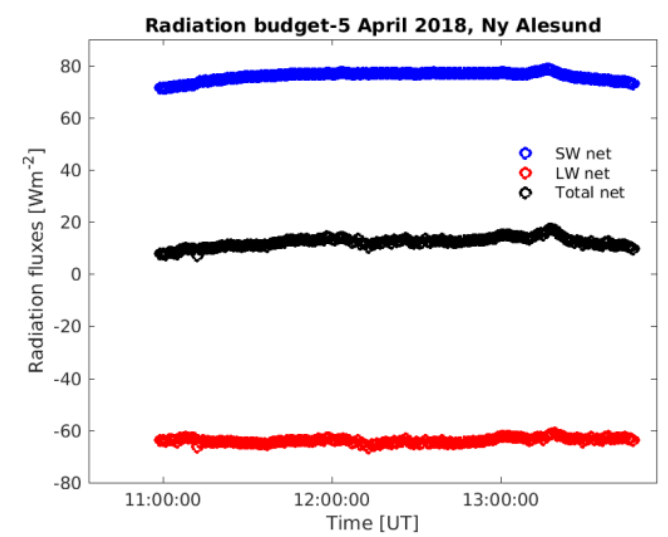

Fig 4: Net radiation budget on ground level at $\mathrm{Ny}-$ Ålesund, 5 April 2018.

SW fluxes resulted in an average positive budget of $76 \mathrm{Wm}^{-2}$, while a negative LW balance $(-64$ $\mathrm{Wm}^{-2}$ ) was found. The combined impact of broadband LW and SW radiation was positive (12 $\mathrm{Wm}^{-2}$ ), suggesting heating at ground level (Fig. 4).

\section{CONCLUSIONS AND FUTURE WORK}

In this, study, aerosol layers extending over a large spatial area in the Arctic were investigated. The retrieved optical properties, indicated quite large and nearly spherical particles. The layers under investigation were persistent, with the evolution of their optical properties not being pronounced. Additionally, their optical properties exhibited weak spectral dependency, especially over Ny-Ålesund, where the layers consisted of more aged particles compared to those observed over Fram Strait. A bimodal volume distribution was derived from the inversion of aerosol microphysical properties, with higher RI and lower SSA compared to other transport events into the Arctic. The inferred microphysical properties can be utilized in closure schemes with in-situ measurements. Hemispheric radiation measurements yielded moderate total heating at the surface of Ny-Ålesund. In the next steps of our research, we will assess the radiative impact of this event at ground and at different atmospheric levels from the perspective of Radiative Transfer Model for SCIAMACHY (SCIATRAN) simulations [16].

\section{ACKNOWLEDGEMENTS}

We gratefully acknowledge the funding by the Deutsche Forschungsgemeinschaft (DFG, German Research Foundation) - Project Number 268020496 TRR 172, within the Transregional Collaborative Research Center "ArctiC Amplification: Climate Relevant Atmospheric and SurfaCe Processes, and Feedback Mechanisms (AC) $)^{3 ”}$, subprojects BO6, CO3 and $\mathrm{BO} 2$.

\section{REFERENCES}

[1] M.C. Serreze et al. Glob. Planet. Change 77, 85-96 (2011)

[2] A. Stohl, JGR 111, 11306 (2006)

[3] A. Hoffmann, PhD Thesis Uni.Potsdam (2011)

[4] I. Stachlewska et al. Atmos. Chem. Phys. 10, $2947-$ $2963(2010)$

[5] J. D. Klett, Appl. Opt. 20, 211-220 (1981)

[6] A. Ansmann et al. Appl. Opt. 31, 7113-7131 (1992)

[7] S. Dahlke et al. Adv. Meteorol. 2017, 4928620 (2017)

[8] C. Ritter, et al. Atmos. Env. 141, 1-19 (2016)

[9] C. Böckmann et al., Appl. Opt. 40, 1329-1342 (2001)

[10] S. Samaras et al. J. Comput. Phys. 299, 156-174 (2015)

[11] D. Müller et al. Atmos. Meas. Tech. 9, 5007-5035 (2016)

[12] M. Maturilli, et al. Theor. Appl. Climatol. 120, 333 339 (2015)

[13] D. Müller et al. JGR 112 D16202 (2007)

[14] C. Ritter et al. TellusB Chem. Phys. Meteorol. 70:1, 1-24 (2018)

[15] J. Lisok et al. Atmos. Env. 140, 150-166 (2016)

[16] V.V. Rosanov et al. J. Quant. Spectrosc. Radiat. Transf. 133, 13-71 (2014) 